\title{
ARGUMENTAÇÃO E DEBATE: REFLEXÕES PARA UMA TEORIA DA DISCUSSÃO SEGUNDO MCBURNEY E HANCE
}

\section{SANDRA MAIA-VASCONCELOS \\ DANNYTZA SERRA GOMES}

Universidade Federal do Ceará

Fortaleza, Ceará, Brasil

E-mail: sandramaiafv@gmail.com,dannytzasg@gmail.com

\section{MARIA LEIDIANE TAVARES}

Universidade da Integração Internacional da Lusofonia Afro-Brasileira campus Redenção, Ceará, Brasil

E-mail: mleidianet@gmail.com

\section{Resumo:}

O objetivo deste estudo foi o de desenvolver um ensaio sobre a obra obra de James H. McBurney e Kenneth G. Hance - Princípios, Métodos e Técnica de Argumentação e Debate, do original inglês Discussion in Human Affairs, editado pela Harper \& Brothers, New York, em 1950. Os autores traçam nessa obra didática uma clara distinção entre os conceitos de discussão e debate, abordando seu significado no contexto da língua inglesa, em busca de soluções e de competição entre opiniões antagônicas. Os autores vão constituir, dessa maneira, uma teoria da discussão fundamentada nas concepções de pesquisa, pensamento construtivo, crítica e cooperação, sem negligenciar a importância do debate, e suas concepções de defesa, raciocínio intencional, propaganda e competição. Ao final da leitura, podemos sinalizar para a característica básica do líder-orador que é conhecer o assunto a ser tratado e assumir uma postura que demonstre segurança e coerência.

\section{Palavras-Chave:}

argumentação, pensamento reflexivo, ensino de língua, discussão, debate.

\section{ARGUMENTS AND DEBATE: REFLECTIONS FOR A THEORY OF DISCUSSION ACCORDING MCBURNEY AND HANCE}

\section{Abstract:}

The purpose of this study was to develop an essay on the work of James H. McBurney and Kenneth G. Hance - Principles, Methods and Technique of Argumentation and Debate, from the original English Discussion in Human Affairs, edited by Harper \& Brothers, New York in 1950. The authors draw in this didactic work a clear distinction between the concepts of discussion and debate, approaching their meaning in the context of the English language, in search of solutions and competition between antagonistic opinions. The authors will thus constitute a theory of discussion grounded in the conceptions of research, constructive thinking, criticism and cooperation, without neglecting the importance of the debate, and its conceptions of defense, intentional reasoning, propaganda and competition. At the end of the reading, we can signal to the basic characteristic of 


\section{DEE Debates \\ em Educação Científica e Tecnológica

the leader-speaker who is to know the subject to be treated and to assume a posture that demonstrates security and coherence.

\section{Keywords:}

argumentation, reflexive thinking, language teaching, discussion, debate.

\section{INTRODUÇÃO}

Este artigo nasce de uma leitura da obra de James H. McBurney e Kenneth G. Hance, Princípios, Métodos e Técnica de Argumentação e Debate, do original inglês Discussion in Human Affairs, editado pela Harper \& Brothers, New York, em 1950. A obra foi traduzida em português por Waltensir Dutra, em 1959. O original é já uma revisão revista e ampliada de The principles and methods of discussion, publicada em 1939. A obra foi escrita inicialmente pelo especialista americano James $H$. McBurney, professor de Arte de falar em público e Catedrático da Faculdade de Eloquência, na Northwesten University. Com seu sucesso, a obra foi reeditada com a importante colaboração do professor Kenneth Hance, Professor de Eloquência na Michigan University.

Os autores traçam nessa obra didática uma clara distinção entre os conceitos de discussão e debate, abordando seu significado no contexto da língua inglesa, respectivamente de busca de soluções e de competição entre opiniões antagônicas. Didática, pois muitos profissionais utilizam em seu cotidiano a discussão e o debate, ou têm a argumentação como instrumento de trabalho. Apenas para ilustrar, podemos citar advogados, professores, juízes, membros do Ministério Público, chefe de vendas, vendedores, jornalistas, publicitários, conferencistas, políticos, administradores públicos ou privados, radialistas, locutores, padres, pastores e demais ministros religiosos. Assim, os autores não somente trabalham com as noções conceituais dos termos, mas também com esquemas de atitudes e conhecimentos que tornem as pessoas capazes de participar adequadamente de uma discussão. Aqui privilegiaremos as noções conceituais apresentadas e amplamente discutidas pelos autores. Algumas atitudes virão a reboque das formulações aqui tratadas.

Em língua portuguesa, vemos, em muitos contextos, uma relação quase sinônima entre os dois termos, discussão e debate, em outros contextos podemos encontrar relação de significado contrária ao sentido em inglês discussão, competição entre opiniões antagônicas; debate, troca de opiniões. Manteremos nesse estudo o significado originalmente atribuído pelos autores, a quem trataremos doravante, por questões didáticas, por M\&H, haja vista tratar esse artigo de uma única obra desses autores, bem como ser esse o foco a ser posto em paralelo com as perspectivas atuais. 


\section{FUNDAMENTOS}

Para M\&H, a discussão forma entre os homens as relações necessárias a que se tornem pessoas, a que aprendam a viver em grupos e vivam em relação com o ambiente. A discussão gera reflexões imprescindíveis à compreensão dos valores implicados nessas relações que retratam o progresso social e científico. Segundo os autores, são quatro as relações básicas que definem o fundamento teórico da discussão: a) pesquisa e argumentação; b) pensamento reflexivo e raciocínio intencional; c) crítica e propaganda e d) cooperação e competição.

Para pesquisa e argumentação, os autores compreendem a existência de uma fronteira que se marca pelo fato de que a segunda começa quando a primeira se conclui. Ou seja, a argumentação só se estrutura logo que o problema é compreendido e sobre o qual se manifesta uma ação. M\&H usam como exemplo para esclarecimento de sua tese os advogados. A argumentação se forma partindo do conhecimento do problema e de suas dimensões íntimas. Assim como o advogado necessita conhecer, por um lado o delito, por outro a legislação que o instrumenta a inocentar ou a condenar o acusado.

Sobre pensamento reflexivo e raciocínio intencional, os autores se referem, sobretudo, à pesquisa. Para $M \& H$, o pensamento reflexivo se refere precisamente à pesquisa por seu caráter construtivo. Paralelamente, o raciocínio intencional fará referência à argumentação, por seu objetivo de justificar e defender um ponto de vista. Logo, enquanto o pensamento reflexivo constrói argumentos, o raciocínio intencional os utiliza com o objetivo da persuasão de um grupo alvo - o que os torna complementares. A discussão se constitui na capacidade que um grupo conquista de pensar junto, reflexivamente, por elaboração conjunta de argumentação. Para Dewey (1933), o pensamento reflexivo é o processo e a argumentação/discussão é o produto.

O terceiro fundamento teórico da discussão para M\&H explicita a distinção entre crítica e propaganda. A crítica tem como pressuposto a visão objetiva do problema e sua análise franca e honesta em todos os seus aspectos. Não se pode afirmar que essa análise seja fácil. Ao contrário, esse objetivo é raramente atingido. A propaganda, como se compreende no senso comum, expressa opinião ou ações que deliberadamente têm o objetivo de influenciar pessoas ou grupos à aceitação de um ponto de vista. Podemos retomar aqui o conceito anterior, sugerindo que a propaganda seria o processo e a aceitação, o produto. Vista assim, a propaganda se afasta do conceito de análise crítica, quando tenta impor um ponto de vista, enquanto a ciência busca verdades e fatos. Desse modo, a propaganda se constitui como sugestão e a crítica científica como constatação. 
Nesse contexto, a discussão estaria muito mais propensa à crítica que à propaganda, apesar de ambas apresentarem aspectos de subjetividade e intencionalidade. A discussão, segundo $M \& H$, não procura influenciar a opinião pública, o que não impede que a análise crítica dos fatos possa levar o grupo, ou parte dele, a mudar de opinião. Como não é motivada por interesses especiais, a discussão se processa por argumentação livre ilustrada por fatos verdadeiros. Acrescente-se, ainda, que a discussão permite ao participante resguardar sua integridade intelectual, além de estimular a reflexão sobre opiniões publicadas.

O quarto fundamento - cooperação e competição - resume as fórmulas anteriores. Para M\&H, a cooperação reúne os conceitos de pesquisa, raciocínio construtivo e crítica, desenvolvidos por um grupo. A competição cria o paradoxo no trabalho crítico e apoia, sobretudo, os conceitos de argumentação, raciocínio intencional e propaganda. A primeira busca a convergência e o trabalho comum. A segunda busca a oposição. Desse modo, podemos compreender a cooperação como fundamento da discussão, e a competição fundamento do debate.

Os autores vão constituir, dessa maneira, uma teoria da discussão fundamentada nas concepções de pesquisa, pensamento construtivo, crítica e cooperação, sem negligenciar a importância do debate, e suas concepções de defesa, raciocínio intencional, propaganda e competição. O estudo comparativo tem como finalidade a exposição das teorias, não a preferência de uma em relação à outra. Sabe-se que em uma pesquisa sempre é necessário dispor argumentos e contradições, a fim de que se chegue a uma verdade. Daí por que afirmamos acima tratar-se de conceitos complementares. É o que constitui a dialética das ideias. Exemplo muito útil são os projetos em geral. Os métodos de preparação de um projeto designam o estudo individual ou de grupo de um problema pela pesquisa, pelo pensamento construtivo, pela crítica e pela cooperação - todos os métodos da discussão. A leitura do projeto por outro grupo pode gerar um debate em que incorram sugestões, oposições e intencionalidades, elementos da competição, com vista a imposições de pontos de vista. O exemplo ilustra o objetivo do trabalho de $M \& H$, que fazemos emergir aqui como Teoria da Discussão.

M\&H definem discussão como "a deliberação cooperativa sobre problemas, por pessoas que pensam e conversam em grupos pequenos ou grandes, sob a direção de um líder, com o objetivo de chegar a um entendimento e a uma ação" (p.25). A definição aponta quatro aspectos a serem explorados mais adiante de forma mais amiúde. O primeiro aspecto diz respeito à discussão como deliberação reflexiva sobre problema. Como já foi dito, o pensamento reflexivo ou construtivo é característico da discussão. Tal associação não explica por si só a cooperação existente entre os termos. Citado por M\&H, Dashiell (1935) defende que as discussões são qualitativamente adequadas a convergirem ao pensamento de 


\section{DEEDebates

uma só pessoa ou à formação de um pensamento coletivo que caracterize o grupo como um só indivíduo. Ou seja, o pensamento reflexivo de um grupo corresponde muito de perto ao de um só membro desse grupo. O que indica a constituição de um pensamento grupal, ou o que Lefèvre (2003) chama de discurso do sujeito coletivo.

Essa análise nos permite chegar à compreensão do que significa discussão em grupo, em suas fases, segundo Dewey (1933). Para esse autor, a discussão se articula em torno de etapas geradoras de convergência. Daí sua defesa em definir inicialmente o problema, delimitá-lo, a fim de esclarecer e precisar o problema antes de tentar analisá-lo. A análise do problema não pode ocorrer antes de sua delimitação e do diagnóstico de suas dificuldades. Encontradas as dificuldades, a discussão começa a acontecer. A compreensão da natureza do problema deve ser feita em termos de relações de causa e efeito, sem perder de vista sempre a solução e a representação dos papéis dos membros do grupo em relação à solução proposta. Enquanto o grupo não convergir no objetivo de solucionar o problema não poderá haver entendimento.

A terceira fase se dará pela sugestão de soluções pensadas e possíveis. $\mathrm{Na}$ discussão, divagações e pronunciamentos inócuos não promovem avanço na tarefa. Por isso é imprescindível que o problema seja conhecido a fundo. A solução pode estar na junção de diversas hipóteses ou propostas experimentais formuladas pelos membros do grupo. O processo reflexivo será a demonstração da capacidade do grupo de sugerir e de aperfeiçoar soluções adequadas.

A quarta etapa do processo consiste em desenvolver racionalmente as soluções propostas. O exame minucioso das soluções e a possibilidade de adequações levarão o grupo a uma solução experimental. As verificações posteriores, formadoras da quinta etapa do tópico de deliberação reflexiva sobre problemas, servirão a comprovar o pensamento do grupo. Essa verificação passa além da discussão, pois toca subjetividades com as quais é preciso ter um cuidado muito específico.

A segunda definição prática de discussão diz respeito àquela em que as pessoas que constituem o grupo pensam e conversam cooperativamente. Para $M \& H$, o pensar cooperativo institui-se a partir da mutualidade de objetivos e esforços conjuntos, o que não implica necessariamente um acordo. Em toda discussão existem diferenças, o que torna o discurso bem salutar e estimulante. Mas o caráter com o qual as pessoas do grupo conduzem as diferenças é determinante para o desenvolvimento cooperativo da discussão.

Como terceira definição, os autores trazem os grupos em pequeno número ou grande número de participantes. M\&H definem que o grupo pequeno permite maior interação, pois todos podem participar. O processo de conversação acontece constantemente. Em grupos maiores, a conversação fica comprometida pelo número 
de participantes, mas ainda assim é possível assegurar um pensamento cooperativo. Instrumentos como painel, simpósio, fórum são especiais para este fim.

A quarta definição põe a discussão como atividade dirigida. Nesse caso, a discussão é dirigida por um moderador que, em si, guarda a palavra cooperativa e conciliatória.

Por última definição, temos a discussão como instrumento de entendimento e ação. A discussão sempre busca uma base de apoio a fim de que valores inerentes aos problemas se mantenham em integração com os fatos. A condução de enunciados elucidativos não implica concordância de opiniões. Embora a discussão procure sempre um ponto de conciliação, no discurso a compreensão dos desentendimentos é tão importante quanto sua solução.

Nessa perspectiva, M\&H vêm apresentar a discussão como uma forma discursiva de chave de problemas. Para tanto, os autores constroem um sistema de formas de discussão reproduzido no quadro 1.

Quadro 1: Valores. Fonte: Dados da pesquisa.

\begin{tabular}{|c|c|c|c|c|c|}
\hline Valores & Valores instáveis & \multicolumn{2}{|c|}{ Valores fixos } \\
\hline Sistemas políticos & Anarquia & $\rightarrow$ & Democracia & $\rightarrow$ & Ditadura \\
\hline $\begin{array}{c}\text { Formas de } \\
\text { conhecimento }\end{array}$ & Ceticismo $\rightarrow$ & Pragmatismo $\rightarrow$ & $\begin{array}{c}\text { Empirismo } \rightarrow \\
\text { Racionalismo }\end{array}$ & Misticismo $\rightarrow$ & Autoritarismo \\
\hline $\begin{array}{c}\text { Atitude } \\
\text { discussão }\end{array}$ & $\begin{array}{c}\text { Dúvida } \rightarrow \\
\text { Crresponsável } \rightarrow\end{array}$ & $\begin{array}{c}\text { Deliberação } \\
\text { reflexiva } \rightarrow\end{array}$ & Negociação $\rightarrow$ & Persuasão $\rightarrow$ & Força \\
(conciliação) $\rightarrow$ & $\begin{array}{c}\text { (adjudicação) } \rightarrow \\
\text { ientífico) }\end{array}$ & $\begin{array}{c}\text { Persuasão } \\
\text { (propaganda) } \rightarrow\end{array}$ & $\begin{array}{c}\text { Ordens e } \\
\text { instruçães }\end{array}$ \\
\hline Resultados & $\begin{array}{c}\text { Confusão e } \\
\text { desordem } \rightarrow\end{array}$ & $\begin{array}{c}\text { Integração } \rightarrow \\
\text { Concessão } \rightarrow\end{array}$ & $\begin{array}{c}\text { Aceitação } \\
\text { voluntária } \rightarrow\end{array}$ & Obediência \\
\hline
\end{tabular}

Podemos perceber nesse esquema uma sequência de aspectos relativos à organização do discurso específico. Se analisarmos cada linha horizontal deste quadro, podemos perceber a lógica com se formam os discursos em uma discussão. Temos, entretanto, de visualizar o quadro nas duas direções, vertical e horizontal, se quisermos compreender a dinâmica do discurso que suscita embate e discussão. 
Vemos inicialmente, na primeira linha, a relativização entre os valores, instáveis e fixos, que formam o pilar de toda discussão. Se acompanharmos as colunas respectivas veremos como se organizam os discursos institucionais. No espaço em que os valores são instáveis, não se pode prever uma organização adequada às demandas sociais. Os discursos desordenados e confusos geram dúvida, ceticismo, crítica irrefletida e consequentemente irresponsável, que deságua em confusão e desordem, o caos na sua forma mais estreita, sem abertura para um entendimento.

No extremo oposto observamos que valores fixos, engessados e imutáveis tampouco provocam reflexão e conduta educativa. Ao contrário, a exemplo da ditadura no sistema político, a imutabilidade é resultante de um autoritarismo inconsequente que se move pela força, restringe desenvolvimento cognitivo da linguagem, é prescritivo e, sobretudo, proscrito, arraigado a regras e exigências que só percebem crescimento na obediência. Podemos dar como ilustração a batalha travada entre os defensores do purismo ortográfico e aqueles que deixam tudo ao laissez-faire. Intermediando esses dois opostos, o quadro de M\&H apresenta três colunas representativas de tolerância. A coluna central intitulada Democracia abrange as duas laterais, na verdade, já que são formadoras de um discurso contínuo que se constrói em torno da experiência de discussão e debate. Vemos que algumas palavras-chave orientam a retomada da voz dos interlocutores, agora não mais restringida pelo poder. Expressões novas surgem, como empirismo, racionalismo, negociação, debate, conciliação, concessão, apenas para citar algumas bastante ilustrativas da intencionalidade da discussão. Como vimos no início desse texto, a discussão toma um conceito de inter-relação e de interação constante no grupo buscando o entendimento.

Vemos na análise horizontal que as formas de discussão caminham da crítica irresponsável, aquela que pode denegrir o processo de discussão, retirando toda e qualquer possibilidade de investimento no entendimento, para o sistema de ordens e instruções, também nocivo ao processo. Vemos que os resultados chegam aos extremos cerceadores da liberdade construtiva do discurso: de confusão e desordem a obediência. No intermédio encontramos três possibilidades de atenuação do radicalismo marcado pelos polos: integração, concessão e aceitação voluntária são condutas que instruem o discurso na direção do entendimento, fim próprio e ideal de toda discussão. Podemos observar, outrossim, que o esquema de M\&H aponta para um estudo sobre os gêneros diferentes nas formas de discussão. Os autores fazem emergir alguns aspectos próprios de discursos científicos, jurídicos e argumentativos, pela proposta de propaganda na persuasão.

Para as formas intermediárias entre os extremos já discutidos aqui, percebemos uma constante busca ora na conciliação, ora na adjudicação, ora na persuasão. Vemos na conciliação a observância do método científico, o que 


\section{DE Eebates

caracteriza rigor de escolha de expressões, de diretrizes em busca do entendimento. Se subirmos um nível no quadro, observaremos as atitudes tomadas para esse fim. São atitudes de deliberação reflexiva, excluindo dessa proposta a dúvida e o uso da força. A reflexão por si só já denota um desdobramento sobre o tema, um movimento de ir e vir nas discussões com fechamento sobre uma deliberação. Na direção das atitudes, a reflexão vai gerar uma negociação entre opiniões diversas no momento mesmo da discussão. Se nesse momento é respeitado o direito de discordarem-se as opiniões, a discussão ganha espaço para um resultado integrado no grupo.

\section{CONDUTA DA FALA NA DISCUSSÃO}

A comunicação humana de ideias e sentimentos se realiza por intermédio de símbolos visíveis e audíveis, ou seja, por meio de sons, palavras, gestos (p. 229) que circularmente se integram segundo as condições de produção, o contexto, o nível de relações entre as pessoas envolvidas, ruídos, conhecimentos prévios. M\&H enumeram alguns elementos do "bom discurso" essenciais ao entendimento entre os participantes de uma discussão:

O primeiro elemento diz respeito a animação e sinceridade. Os autores integram a esses conceitos as noções de disposição física em uma apresentação oral, em uma exposição ou comunicação em público. O falante sempre envolve a plateia de uma energia própria e segundo as tarefas pelas quais tem interesse. A demonstração de sinceridade indica por sua vez um objetivo verdadeiro e uma intenção honesta. Animação e sinceridade no momento da fala despertam atenção e respeito no ouvinte, pois são tomadas como prova de conhecimento, franqueza, engajamento e consideração pelos ouvintes. Contrariamente, a lentidão e a jactância são, segundo os autores, repetidamente interpretadas como ostentação, indiferença e duplicidade.

Todo e qualquer problema definido por um grupo como merecedor de discussão será digno de esforço e interesse do grupo. Um só participante desinteressado ou indiferente torna difícil o raciocínio conjunto do grupo. 0 mutualismo na discussão indicia ao mesmo tempo a disponibilidade do grupo em se integrar. Um discurso animado e sincero representa grande contribuição à discussão: a responsabilidade estabelecida pelo privilégio da participação no grupo.

O segundo elemento essencial ao bom discurso é apontado pelos autores como a objetividade. Para $\mathrm{M} \& \mathrm{H}$ "tanto a objetividade física como a mental contribuem para um discurso eficiente". O orador, no momento de sua elocução, não pode esquecer o essencial: o público. Ele deve dirigir-se a todas as pessoas com quem troca ideias na discussão. Qualquer forma de imposição quebra o objetivo e a objetividade da discussão. Para o público é muito importante sentir-se concernido a 


\section{DEEDebates

todo momento. Ao discursar, devemos levar o auditório a se sentir como se estivéssemos falando com cada uma das pessoas ali presentes. Quando o discurso advém de uma reunião prévia, o orador deve se dirigir alternadamente aos diversos subgrupos e segundo suas opiniões, fazendo progredir um pensamento coletivo e estimulando o entendimento.

Cabe ao orador a responsabilidade levar o grupo a se sentir integrado nas conversações e evitar conversas isoladas que tendem a destruir a unidade do grupo. É ainda papel do líder buscar alcançar o que os autores M\&H chamam de "objetividade mental" (p.231): a metaconsciência do dito no momento em que é dito, não só para si, mas para os ouvintes também; a dispersão prejudica a compreensão e fragiliza a comunicação. O bom discurso busca atentamente provocar nos ouvintes um espírito alerta e firme, longe da vaguidão e da indiferença.

$\mathrm{O}$ terceiro elemento que emerge nas teorias de $\mathrm{M} \& \mathrm{H}$ sobre o bom discurso concerne ao tom de voz. Para os autores, "a variedade de voz é característica de uma comunicação animada, sincera e objetiva, e é ao mesmo tempo causa e efeito dessa comunicação". Os autores consideram que entre falante e ouvinte existe uma relação de reciprocidade que deve ser trabalhada, levando em conta variações de força - volume ou altura - alcance, qualidade e tempo - média, duração e pausa. Muito da transmissão dos significados do discurso é consequência direta do uso desses fatores. Não defendem os autores que o falante modifique sua dicção pessoal, mas que saiba valorizar a voz que tem em seu discurso falado. Defender uma ideia com uma voz monótona e sem entoação e ritmo adequado ao objetivo será menos eficiente que fazê-lo com uma voz ritmada por ênfases, distinções, emoções, sentimentos de engajamento com o público, e atitudes relacionadas ao assunto tratado. Os ouvintes reagem imediatamente à voz do orador, muitas vezes caracterizando sua personalidade segundo sua fala. Uma boa reação levará o ouvinte a ter uma melhor apreciação do assunto tratado; uma má reação poderá, ao contrário, levar o ouvinte a repugnar o assunto em questão e a cair no vago.

O quarto elemento apontado pelos autores diz respeito aos gestos do orador, líder ou falante. Os oradores ativos, sinceros e animados têm uma tendência a mover-se de forma vigorosa, sem exageros, levando o público a manter-se também ativo. Um corpo muito parado, relaxado, não se presta a uma comunicação vigorosa, estimulante para o público. É preciso uma boa medida do uso dos gestos para tampouco exagerar ou demonstrar exaltação ou agitação. Um bom sorriso do orador tende a provocar sorrisos na plateia, assim como um gesto rude levará a plateia ao constrangimento. Um exemplo utilizado pelo orador durante seu discurso deve ser de interesse espontâneo dos ouvintes. Reações de aprovação ou desaprovação são facilmente percebidos por gestos dos ouvintes, como balançar a cabeça afirmativa ou negativamente. Assim o discurso se apresenta nos gestos do orador como marcas 


\section{DE Eebates

de imposição de ideias, de trocas, de busca de uma aprovação do público, e para os ouvintes implicando em interesse, cumplicidade, impaciência, tédio, aprovação ou reprovação.

Como quinto elemento do bom discurso, os autores apresentam a audibilidade. A audibilidade é essencial, haja vista que nada é mais prejudicial à discussão do que os ruídos, quando as pessoas não conseguem fazer-se ouvir. Os autores associam essa dificuldade ao fato de muitas vezes os oradores se concentrar em pessoas na plateia que estão mais próximas deles, adequando a altura da voz a essas pessoas, e assim prejudicam a audibilidade das demais. É ainda de importância fundamental a atenção sobre a boa articulação. Reuniões pouco formais tendem a promover um relaxamento dos critérios de escolha vocabular, de cuidado de pronúncia que podem influenciar negativamente no processo de comunicação. Uma falha na recepção de mensagem torna a discussão deficiente ou ambígua.

\section{Atitude e Comportamento na Discussão}

Nesse momento, os autores fazem emergir a relevância dos papéis dos interlocutores na discussão. A atitude dos participantes em uma discussão é o ponto fundamental no processo. Para $M \& H$, se os participantes adotarem sempre atitudes construtivas o problema passa a parecer relativamente simples; isso ocorre porque o discurso na reunião reflete consideravelmente as opiniões, as posturas e as atitudes dos participantes. Posturas e atitudes egocêntricas, individualizadas e competidoras não constroem uma discussão em grupo. Ainda que os participantes tentem atitudes dissimuladas de entendimento ou pensamentos forçados de tolerância, ao término a objetividade e o desejo de trabalho em conjunto serão fadados ao fracasso mais cedo ou mais tarde.

Os autores trazem uma reflexão acerca da proximidade entre a discussão e o método científico. Segundo $M \& H$, as atitudes que constroem o comportamento coletivo, colaborativo, na pesquisa científica, aplicam-se também à discussão. Construções argumentativas de julgamento, explicações alternativas, curiosidade intelectual, amplo uso da observação em busca de inter-relações significativas, reconhecimento de valores dos diferentes pontos de vista, reconhecimento das suposições, das oposições, das hipóteses e teorias, tratamento crítico e analítico, imaginação fértil para o levantamento de hipóteses, procedimentos sistemáticos, descrições simples fundamentadas em descrições interdisciplinares, análises de problemas são elementos e atitudes que levam ao que os autores denominaram conclusões responsáveis, a saber: conclusões limitadas às informações prestadas e disponíveis, considerando possibilidades de erros como preconceitos, informações insuficientes, desprezo dos exemplos negativos, exemplos não representativos, efeitos do acaso, esquecimentos, desconfiança ou não credibilidade no testemunho, 


\section{DE Eebates

relações paralelas e falhas. Os autores também chamam a atenção para o fato de ser imprescindível evitar situações de tudo ou nada, evitar aparências de exatidão que só destroem as relações e reconhecer que toda comunicação pode ser falível, levantando a questão do cuidado que se deve ter na valorização de testemunhos dentro da dimensão que esses relatos não impliquem privilégios por um ou por outro lado do grupo.

$\mathrm{Na}$ condução dos discursos, os autores lembram a importância de algumas atitudes:

a) ter em mente o bem comum, tentando descobrir, como na pesquisa científica, os objetivos do grupo, na situação em que se encontra. O discurso a ser mantido pelo grupo deve abranger todas as diferenças e convergências dos membros de maneira a tornar-se um discurso homogêneo, respeitadas as diversidades.

b) assumir a parte de responsabilidade no grupo. O grupo exige um líder que deve ter um discurso coerente e engajador. O líder que tudo faz numa discussão é inútil, pois dessa maneira o grupo não existe, e não existindo o grupo, o líder também se dissolve. O líder promove no grupo uma discussão dinâmica, dialética e vibrante.

c) pensar antes de falar, mas não deixar para manifestar-se somente ao final das discussões. As ideias podem ser lançadas na discussão, mas sem imposições precipitadas, tampouco sem ausência deliberada. O ponto ideal se coloca na boa medida da manifestação das ideias. Um assunto deve ser tratado segundo sua relevância e segundo uma boa e coerente formulação prévia do pensamento. Daí por que os relatórios e as atas são sempre escritos ao final da discussão, quando a maior parte das ideias já foram expostas, desenvolvidas e discutidas.

d) evitar tomar as ideias a expor como pensamentos pessoais, íntimos, o que dificulta seriamente a discussão objetiva. Nesse momento os elementos argumentativos entram em questão, haja vista ser muito comum a defesa de um ponto de vista como algo pessoal, podendo provocar inclusive ressentimentos interpessoais quando há discordâncias. Se isso ocorre numa discussão, o grupo se divide e se fragiliza, rompendo o diálogo e a possibilidade de uma discussão conjunta. Não é fácil manter a objetividade nesse momento. Os autores sugerem expressões como [...] No momento, penso que [...], Pelo que tenho observado [...], Estou somente pensando alto, mas parece que [...], que segundo afirmam, podem atenuar reações de contradições muito agressivas.

e) como última atitude, a escuta aparece como fator essencial do entendimento. O bom ouvinte, segundo os autores, é tão importante quanto o bom orador. No esquema da comunicação trabalhado por Jakobson, o receptor, ou ouvinte 
está entre os seis elementos essenciais da comunicação. Quaisquer interferências dentro desse processo geram uma recusa que pode vir a ser irreversível para o grupo. Daí M\&H chamam a atenção para o fato de que não se devem ouvir os outros membros com a intenção prévia de refutar suas ideias, mas, antes, de compreendê-las, de construir por intermédio delas uma postura coerente e responsável para o grupo.

As atitudes sugeridas pelos autores para o funcionamento da discussão levam a questões múltiplas sobre como, finalmente, organizar uma participação que seja auxiliadora à discussão. Um fato que chama a atenção é o uso de registros e gravações. As pessoas tendem a ser mais reflexivas quando sabem que estão sendo gravadas suas manifestações. Os autores trabalharam sobre centenas de registros para chegarem a essa conclusão. Para $\mathrm{M} \& \mathrm{H}$, o fato de se sentirem registrados promove um maior cuidado nas contribuições que venham a fazer ao grupo, mas também uma maior timidez na manifestação. M\&H chamam a atenção para alguns fatores que podem contribuir para a segurança da discussão do grupo: contexto, essencial para que o grupo compreenda a contribuição apresentada; informações complementares adequadas à compreensão de uma nova ideia - quando ocorre falha nas informações, surgem questões do tipo [...] que isso tem a ver como que estamos discutindo?; contexto pessoal, muitas vezes imprescindível à compreensão de uma opinião ou atitude tomada por um dos membros do grupo.

Esses fatores não implicam necessariamente que haverá uma boa discussão em grupo. Cabe nesse momento ao líder fazer com que haja uma convergência. Isso pode ser trabalhado, segundo $\mathrm{M} \& \mathrm{H}$ sob a perspectiva do que chamam Relevo. Para os autores, é dever do líder sublinhar e reduzir a fim de dar relevo à discussão. Do longo discurso de um dos membros deverão ser postos em relevo, após redução de expressões não judiciosas, pouco importantes, enganosas ou equivocadas e pouco construtivas, as ideias de importância real para o assunto tratado. A tentativa de tratamento de todas as informações trazidas e apresentadas forma um turbilhão de digressões que finalizam por destruir o discurso do grupo. Assim, colocar assuntos de menor importância em segundo plano é tão essencial quanto dar relevo ao que realmente é significativo.

As suposições formam mais um grupo de atitudes sugeridas pelos autores. As suposições são presentes de forma implícita em todas as discussões, ainda que fiquem resguardadas de publicação ao grupo, ou em conversas paralelas entre os membros e não divulgadas. É bom estar alerta para o fato de que suposições errôneas podem provocar erros crassos. Se o líder compreende que determinada premissa é óbvia, de imediato ele isola e submete o grupo a seu ponto de vista. Os autores apontam o exemplo do Nazismo. Em uma discussão, o orador pode supor que todos sejam contra o movimento alemão liderado por Adolf Hitler e tecer 


\section{DE Eebates

comentários acusativos a esse sistema. Modernamente, poderíamos cometer o erro de supor que todos são a favor da invasão ao Iraque pelos americanos. A posição do líder em seu discurso depende da aceitação do grupo a que fala. Ouvidas as opiniões sobre o tema, o líder poderá construir uma linha de raciocínio bem estruturada que não venha a ferir opiniões.

Por outro lado, as suposições podem servir de instrumento para a argumentação. No processo comunicativo, o orador deve utilizar-se de suposições, sem exigências de provas, em forma de hipóteses até, que incidam sobre os objetivos da discussão, mas que não comprometam a comunicação do grupo. Os autores sugerem expressões como [...] supondo que o senhor tenha razão, como faremos para atingir o objetivo? , ou [...] não concordo como senhor, mas gostaria de ouvi-lo um pouco mais [...]. As suposições assim são elementos de continuidade da reflexão do grupo.

Sabe-se que o grupo sempre busca semelhanças entre os membros. Para $M \& H$, as semelhanças podem ser compreendidas a partir do ponto de vista da integração e da compreensão. As diferenças muitas vezes são mais ilusórias que reais, porém se mantêm pelo esforço de pessoas que acreditam, sobretudo no desacordo e nas divergências. A identidade é um dos elementos essenciais ao grupo, mas não deve ser visto ou trabalhado como acordo completo, ilimitado, que paralisa a discussão em alguns pontos. Aparece geralmente ligada a expressões como "concordo totalmente", "sem sombra de dúvida", "faço minhas suas palavras". Em geral as consequências são bem graves e quase nunca revistas. O acordo limitado, com restrições, toma formas mais variadas, que podem ser descritas por expressões como "isso, e mais...", "sim, e, além disso, ", "certo, mas também", que demonstra a verdadeira participação do grupo. As ideias são aceitas, mas com restrições bem definidas e esclarecidas. A aceitação com restrição é o que ocorre com mais frequência em uma discussão.

Ainda como fator de relevância para a discussão está a dissensão. As dissensões são tão importantes quanto as identificações e semelhanças. São marcadas essencialmente por oposição ou por dissensão limitada. Na oposição ocorre desacordo total, sem espaço para a discussão, para a troca de ideias. Ou seja, é radicalmente o oposto de identidade. Para identidade a única opção é o sim, para a oposição o não. Na dissensão limitada, vê-se que a questão não se reduz uma resposta única e irrecorrível, mas a possibilidades. Assim, expressões como [...] não concordo, embora deva admitir que [...], apesar de não ser de sua opinião, quero acrescentar que, ou ainda, do ponto de vista do orador e não do ouvinte, quando procura na plateia a quem se dirige certa cumplicidade nas ações, em expressões como "se houver o apoio", "se trabalharmos em conjunto" são exemplos de dizeres que engajam clareza das relações, tolerância e respeito pelo outro. 
Numa discussão, a divisão de um assunto em partes é também um recurso de auxílio à compreensão do todo. Pela divisão pode-se chegar á análise e á síntese, no esclarecimento das semelhanças e dissensões. A divisão constitui-se a base da maioria das organizações, por exemplo, a departamentalização nas empresas, nas instituições públicas e mesmo nas famílias. Como cada membro do grupo tem uma função, na discussão, cada parte do discurso também terá uma função específica no conjunto. M\&H sugerem duas possibilidades de divisão: partilha e disjunção. A partilha pode ser definida como a separação do todo em suas partes integrantes, um organizador de tarefas na discussão, em que de um lado se expõem os problemas a serem discutidos, de outro se organizam os grupos de resolução, esclarecimento e formação de unidade discursiva final. A disjunção ocorre de forma mais compactada. Os discursos não se cruzam, intercalam-se entre certo e errado ou entre alternativas. Formam-se dois elementos novos no discurso: o raciocínio através de dilemas e o raciocínio residual. O dilema ocorre quando as alternativas rigorosamente duas - são indesejáveis ou impossíveis de manter. O raciocínio é residual quando todas as alternativas são postas, apenas uma é indesejável, e será defendida. Quando usado adequadamente, o raciocínio residual serve para focalizar a atenção dos membros do grupo e refletir sobre as demais alternativas.

Os disparates e variações nas informações são um desafio às divisões categóricas. As classificações arbitrárias são características de informações disparatadas. O grande risco reside no fato de que 1) essas classificações desfiguram e simplificam excessivamente os fatos, sendo, portanto, enganosos; 2) a aplicação dessas classificações pode levar a uma atitude injusta em relação ao problema apresentado. Um bom exemplo para informações imprecisas ou disparatadas pode ser encontrado no enunciado abaixo, que servirá de base para o conjunto das análises dos fatores previamente discutidos:

- O sistema de cotas nas universidades promove a igualdade social de direito de acesso ao ensino superior público.

A declaração pode ter reações divergentes entre os ouvintes. Primeiramente, pode ser adotada uma concordância - identidade - imediata e total que ratifique o que foi dito. Todos concordam com a opinião expressa. Em segundo lugar pode ser vista contrariamente, como uma dissensão. Se é necessária a imposição do sistema de cotas para garantir a igualdade de direitos, então essa é mais uma forma de desigualdade. Desse ponto de vista pode-se considerar o comentário como oposição. Entretanto, se se considerar a possibilidade de uma visão adicional, o referencial se 
torna outro. Veem-se assim, para os tipos discutidos pelos autores, duas possibilidades:

A primeira diz respeito ao acordo limitado: o sistema de cotas certamente é uma solução para a urgência do problema da exclusão social, mas não se deve deixar de entrever nessa atitude apenas um paliativo para um problema que não vai deixar de existir. A segunda possibilidade concerne à dissensão limitada: poder-se-ia dizer que o sistema de cotas é mais uma forma de desigualdade, mas de imediato dá oportunidades aos excluídos. Ou seja, a organização do discurso dá um caminho diferente a cada intervenção. Para $\mathrm{M} \& H$ essa organização permite evitar generalizações apressadas e divisão arbitrária. Mas segundo os autores, às vezes é necessário impor uma lei a fim de evitar o que chamam de "violência do caos" ( $p$. 269).

Outro risco fica em torno da retração e correção. Os autores comentam que em geral sempre há exemplos de pessoas que, sendo participantes de uma discussão, embora tenham provas incontestáveis de que estão erradas, não admitem o erro, não modificam suas posturas e seu discurso, muitas vezes perdendo o controle e assumindo um discurso agressivo com alterações no tom da voz. Como advertem $\mathrm{M} \& \mathrm{H}$, mesmo quando os participantes afirmam reconhecer o erro, com frequência esse reconhecimento é acompanhado de longa explicação com finalidade atenuá-lo. Os autores sugerem formas de participação na discussão que tornam viáveis aos oradores posições indefensáveis:

1) evitar declarações formais e a aparência de uma opinião irrevogável, a menos que tenha absoluta certeza do assunto;

2) apresentar a proposição sobre a qual não está muito seguro como uma ideia que o grupo poderá vir a examinar ou como uma ideia sugerida por outros;

3) tomar as posições em forma de hipóteses, segundo as suposições apresentadas;

4) procurar aceitar, na medida do possível, a posição do orador, ao enfrentá-lo;

5) procurar um terreno comum para o qual, numa situação indefensável, possa retirar-se;

6) propor revisões e modificações;

7) dar ao orador a oportunidade cômoda de reconsiderar sua posição.

As sugestões acima defendidas podem como admitem os autores, parecer concessões à fraqueza de opiniões, mas podem ser de grande utilidade na reorganização discursiva que promova uma conciliação de dissensões persistentes. Para $\mathrm{M} \& \mathrm{H}$, os participantes de uma discussão podem tender a manter-se rígidos em um discurso por não saberem como reorganizar suas falas de modo a conciliar, ou simplesmente por acharem difícil sair do grupo de forma discursiva. Vejamos, pois 
um exemplo concreto a fim de esclarecermos quaisquer dúvidas que possam se estabelecer.

O uso deliberado de agentes biológicos - bactérias, vírus ou toxinas produzidas por microrganismos - para causar medo, doença ou morte é um ato terrorista que passou a preocupar a população mundial, principalmente com o envio de cartas contendo o bacilo de Antraz. Após o atentado de 11 de setembro em Nova York, terroristas buscaram dominar esse arsenal biológico por ser mais letal que muitas armas de fogo. Milhões de dólares foram gastos em investigações e guerras que tiveram como mote as armas químicas. Entretanto, o saldo do bioterrorismo é um enorme fracasso em termos quantitativos: nas últimas seis décadas esses atentados mataram cinco pessoas e 33 cabeças de gado. Do ponto de vista ideológico, isso representa muito, mas do ponto de vista econômico é uma taxa irrisória. Citaremos aqui, como texto para estudo desses conflitos, uma reportagem da revista Ciência Hoje, de outubro de 2007, e intercalaremos entre colchetes os comentários sobre o método supracitado.

O bioterrorismo é um tema frequente nos meios de comunicação, muitas vezes tratado de modo sensacionalista. Esse tipo de ato terrorista passou a preocupar a população após o atentado às Torres Gêmeas, seguido de atentados com o Antraz nos Estados unidos, em 2001. [constatação sobre o assunto]; No entanto [dissensão], embora algumas estimativas a respeito dos possíveis impactos de ataques com microrganismos patogênicos sejam apavorantes, até o momento essa modalidade de terrorismo não tem representatividade entre as armas de destruição em massa [dissensão], que, segundo o governo norte-americano, o ditador iraquiano Saddam Hussein produzia, e seriam em princípio destinados à guerra biológica, e não ao bioterrorismo [dissensão]. É preciso salientar que o bioterrorismo inclui não apenas ataques contra populações humanas, mas também contra animais de criação e safras[concordância]. Nas últimas duas décadas, vária ameaças ou atentados bioterroristas ocorreram no mundo, mas em quase todos os casos não atingiram o objetivo de matar pessoas [constatação]. Após os ataques reais nos Estados Unidos, pessoas irresponsáveis em muitos países, inclusive no Brasil, aproveitaram o ocorrido para fazer brincadeiras de extremo mau gosto, enviando envelopes com pó branco e a mensagem falsa de que se tratava de antraz [tomada de posições em forma de hipóteses]. Esses atos causaram medo aos destinatários dessas cartas e muito trabalho caro e desnecessário a sistemas nacionais de segurança e a laboratórios[constatação]. Até agora, as ações dos bioterroristas produziram baixas em apenas dois atentados: os promovidos pelos seguidores de Rajneesh em 1984 (apenas adoecimentos, sem mortes) e os do criminoso desconhecido que enviou as cartas com antraz em 2001[constatação]. Os vários atentados da seita Aum Shinrikyo com armas biológicas, no Japão, falharam, embora contassem com uma equipe de microbiólogos pós-graduados e com todo o 
equipamento de laboratório necessário. O fato de que mesmo um grupo com tantos recursos não conseguiu produzir nenhuma arma biológica que funcionasse direito parece indicar [procurar um terreno comum] que o bioterrorismo, apesar da preocupação e do sensacionalismo que desperta, não representa uma ameaça tão drástica [propor revisões e modificações].

Vemos pela distribuição acima que a mensagem passa por variadas fontes comunicacionais de intencionalidade. Ora se trata de uma concordância, ora de uma dissensão, ora de constatação do referente, ora por tomada de posição. Esse passeio por estratégias de convencimento a que se presta todo e qualquer gênero de texto articula a marca discursiva do texto.

\section{ORIENTADOR, DISCURSO E DISCUSSÃO}

As relações de poder sempre aparecem na literatura como relações discursivas - fala é poder. Sem entrar no mérito das abordagens notadamente marxistas, será mantida aqui a abordagem de $M \& H$ nas relações de liderança e responsabilidade social, temperança de ideias, habilidade de análise e síntese, de conciliação e raciocínio rápido nos momentos de conflito, além de, obviamente, inspirar confiança e respeito. Os autores acrescentam como característica essencial do líder a compreensão do caráter democrático da discussão e o domínio da palavra/discurso como instrumento de liderança em que o sujeito-líder caminha na direção de conseguir atingir seus objetivos com seus próprios recursos.

Os autores elencam quatro elementos constituintes da liderança pelo uso da discussão:

1. A primeira diz respeito à clareza quanto ao papel do líder: estimular os participantes para que, num grupo de discussão, as falas/discursos proferidos gerem uma discussão estimulante e proveitosa. Isso acontecerá, sobretudo porque o líder desenvolverá nos participantes um interesse pelo assunto. Sua argumentação deverá conter elementos de clareza e precisão relativos aos interesses do grupo.

2. A segunda característica é a clareza quanto ao objetivo da discussão, que poderá ser em presença do grupo ou como participação indireta. A vantagem da discussão em presença é a resposta imediata, feedback necessário à construção de um diálogo amplo, à conversação e à sociabilidade. M\&H defendem que a discussão é uma atividade comunicativa essencialmente ligada à solução de problemas e as tarefas do líder são determinadas basicamente pelo engajamento discursivo que manterá entre os participantes do grupo, tanto pela organização das ideias aí discutidas, quanto pela manutenção do discurso conciliatório. Somente pela conciliação se pode no 
grupo atingir o objetivo central da discussão, que é a solução de problemas, conforme já foi mencionado acima.

3. Ligada a essa busca de solução, surge a terceira característica apontada por $M \& H$, concernente ao caráter do grupo. O líder deve sempre procurar formar no grupo sua autonomia a fim de que, em sua ausência, o grupo possa funcionar sem liderança. Esse procedimento só será possível num grupo bem informado e articulado, com experiências em discussões. Nesse caso a intervenção do líder deve servir de conexão entre pontos de divergência, ou ainda de ponto de equilíbrio entre os participantes mais ativos, mais comunicativos e mais falantes e aqueles que, às vezes por falta de informações pertinentes, ficam relutantes em falar e acabam ficando à sombra da discussão. O líder servirá como orientador hábil nesse processo de comunicação.

4. Como quarta característica os autores ressaltam que é preciso e importante reconhecer que cada líder obterá seus melhores resultados por métodos diferentes, segundo sua própria personalidade. O discurso do líder, como já foi defendido anteriormente, deve ser sincero e engajador. Alguém de personalidade severa, ou de espírito didático, poderá ter resultados desastrosos ao tentar forçar um senso de humor que não lhe é natural.

\section{TÉCNICAS dE PRÁtICAS PARA UMA DISCUSSÃo PROVEITOSA}

Como líder do grupo, o orientador deve manter uma postura discursiva/comunicativa coerente e segura, desde a abertura da discussão. M\&H apresentam sete métodos que consideram úteis no momento de abertura da discussão em grupo. Os autores apresentam para cada método alguns exemplos que serão resumidos aqui para melhor apreciação.

A discussão, como se sabe, sobrevém de um questionamento. Como primeiro método, os autores ressaltam a importância de apresentar, interpretar e indicar a relevância da pergunta lançada. Essa forma é, segundo $M \& H$, a mais simples e a mais direta de iniciar a discussão. Parte-se de um questionamento mais abrangente e chega-se a uma questão direta, possivelmente dirigida a um membro específico do grupo.

O segundo método defendido pelos autores nesse texto é sobre a importância de apresentar um conjunto de questões específicas que formam o contexto da discussão. Esse método traz a vantagem de focalizar o interesse do grupo sobre assuntos importantes, ao mesmo tempo em que delimita a discussão em torno desses assuntos evitando digressões que só prejudicam o bom andamento da discussão. Cabe ao líder nesse momento declarar os pontos de discussão e classificá- 


\section{DEEDebates

los em ordem de importância a fim de que, caso a discussão sobre um dos pontos se prolongue, não haja prejuízo no processo.

M\&H sugerem como terceiro método de abertura de uma discussão a citação, que poderá advir de uma frase de destaque em um texto, um aforismo, uma manchete de jornal, um verso de um poema, um provérbio ou qualquer outra expressão de efeito que sintetize o tema geral a ser discutido. Partindo desse mote, o problema será exposto e discutido, cabendo ao líder fazer com que o grupo tenha uma discussão equilibrada e moderada (p. 287).

Iniciar a discussão com um fato específico, o relato de um acontecimento ou a explanação de um conflito existente é o quarto método sugerido por $\mathrm{M} \& \mathrm{H}$. para os autores, devem ser apresentadas logo de início as causas imediatas da discussão. [...] Isso capitaliza e dá oportunidade e sentido à introdução (p. 287). O uso do exemplo engrena mais facilmente o sentido da discussão, sobretudo se o exemplo for retirado da realidade e da atualidade. O grupo participa das discussões quando se sente concernido pelo assunto.

A definição inicial do problema é o quinto método sugerido por $\mathrm{M} \& \mathrm{H}$. Os autores argumentam que desde que haja um acordo entre os participantes de um grupo sobre a definição do problema "o grupo pode passar imediatamente" à sua análise. Havendo divergências ou diferenças de opiniões, o líder deve colocá-las em evidência para que sejam analisadas. A análise das diferenças e das divergências promove o crescimento do grupo, desde que o líder mantenha em seu discurso próprio a prerrogativa de considerar o discurso do grupo. Os autores sugerem que questões estimuladoras podem ser lançadas a fim de dar aos participantes sua responsabilidade. Perguntas como "vocês acham que seja pertinente discutirmos o problema?" ou "como podemos confrontar as diferenças em prol do crescimento do grupo?" são estratégias que poderão manter o processo comunicativo sempre atualizado.

Para o sexto método, M\&H apresentam a relevância de citar um caso especial, um exemplo bem conhecido que pode tanto ser histórico como atual. Numa discussão que tivesse como tema a leitura, a violência, a corrupção ou as relações humanas, o líder terá certa facilidade em encontrar exemplos pontuais, históricos ou atuais, ou ambos, para construir sua argumentação. Quanto mais familiarizado com o tema o participante se sente, mais ele desenvolve suas habilidades comunicativas e mais ele se sente capaz de apresentar opiniões e pontos de vista sobre o assunto. Um exemplo citado pelo líder serve para despertar o interesse pelo problema e dar início à discussão. A maioria das pessoas reagem mais prontamente a exemplos concretos e casos específicos (p. 289). Uma vez iniciada a discussão, os argumentos vão aparecendo em evolução constante com os acréscimos e as contribuições dos participantes. O líder deve estar atento para que a discussão não fuja ao tema inicial, 
sem, no entanto, fazer interferências sobre as falas dos participantes que possam bloqueá-los em suas ideias. O líder deve orientá-los no sentido de uma análise mais ampla do assunto sem perda do foco.

O choque de opiniões é o sétimo método sugerido por M\&H para dar início a uma discussão de qualidade. Não apresentadas de maneira opositora, as opiniões podem ser trazidas ao grupo sem juízo de valor, concordância ou discordância do líder. Cabe ao líder expor dois ou mais pontos de vista, ou pedir aos participantes que exponham, controlando as reações do grupo opositor para que a exposição não se transforme num violento caos. Os autores defendem que esse método [...] tem grande utilidade nas discussões muito amplas, porque esclarece a posição inicial de cada participante além de revelar logo de início as diferenças de opiniões. As diferenças devem enriquecer o processo, mas existe o risco de os participantes se comprometerem prematuramente com reações, bruscas e depois se verem diante do embaraço de não ter como voltar atrás, de modificar ou mesmo discutir suas opiniões, à medida que a discussão avança.

Nessa ordem, os autores organizaram um conjunto de métodos para DAR ORDEM, DIREÇÃO E SENTIDO À DISCUSSÃO. Essa tarefa, segundo M\&H, é a mais trabalhosa, a mais árdua e a mais importante do líder. Isso implica evitar que a discussão se transforme numa reunião caótica, confusa, desconexa e assistemática. Num grupo de discussão, todos os participantes estão com o pensamento em fase de reformulação, não cabendo, portanto, julgamentos apriorísticos e precipitados. 0 momento da discussão tem como objetivo, já bastante repetido aqui, a solução de problemas. Logo, a construção do pensamento dirigido à busca de soluções é o caminho a ser seguido. Cabe ao líder estimular por argumentação centrada e coerente o pensamento criador dentro de determinada linha geral de desenvolvimento que, se não neutralize, pelo menos atenue as opiniões.

Segundo $M \& H$, "uma insistência pedante em questões de ordem pode sufocar o esforço criador". O líder não pode controlar arbitrariamente as participações sob pena de prejudicar o crescimento do grupo. Por outro lado, a discussão não poderá acontecer sem direção, sem a presença de um líder que sirva de fiel da balança que garanta o equilíbrio, a fim de que as opiniões não se desenvolvam ao "sabor das circunstâncias" não levando a resultado algum. A grande questão-tarefa do líder é desenvolver uma orientação do pensamento coletivo sem sufocá-lo. Para tanto, os autores apresentam cinco métodos (p.291).

O primeiro método proposto consiste em adotar um plano geral da discussão, mas fixo, respeitando as flexibilidades possíveis e necessárias. Os autores sugerem como melhor linha geral seguir as fases do pensamento reflexivo: definição, análise, hipóteses ou soluções, desenvolvimento racional das hipóteses e experiências ou solução. Seguindo essas fases, a discussão tem começo e fim definidos, o 


\section{DEE Debates

desenvolvimento é ordenado e sistemático e o resultado é garantido. Esse é, segundo os autores, o melhor método para desenvolver hábitos de raciocínio coordenado.

O segundo método, de "choques e consolidação" é sugerido como a oportunidade de se trazerem à tona as questões mais interessantes ou mais polêmicas deixando que o curso da discussão seja em boa parte improvisado. Apesar da aparente desordem, o método de choque pode dar resultados positivos surpreendentes. O líder deve estar atento a que as opiniões expressas sejam argumentadas no sentido da construção do grupo. Se não for bem orientada, a discussão pode ser um fracasso total. Para que o resultado seja positivo, o líder deverá ter um sentido aguçado das questões que levantem o interesse do grupo e constante habilidade de síntese a fim de que as opiniões do grupo sejam consolidadas passo a passo e à medida que a discussão prossegue. Para os autores, "duas habilidades essenciais são necessárias ao líder: fazer falar [...] e consolidar o que foi dito. Habilidade essa que exige muito do líder: espírito alerta e agilidade mental extraordinários. Os participantes falam o que querem, no momento em que querem e do modo que querem falar. "O líder é quem vai sumarizar" e estabelecer relações entre os assuntos ao longo do toda a discussão e simultaneamente a ela. 0 método é desordenado e não deve ser seguido por alguém que não tenha capacidade de síntese. $\mathrm{O}$ conflito pode ter um resultado interessante, estimulante e adequado, mas pode também ser inconsequente e sem nenhuma utilidade prática.

O terceiro método proposto por $M \& H$ sugere a transição de ideias e de áreas de discussão. O risco existe nesse caso e decorre dos pontos críticos que a mudança incorre na organização. Para os autores, [...] os novos assuntos devem usualmente ser relacionados com o assunto que o precede [...] salvo em situações em que essa relação já aparece claramente. O não estabelecimento dessas relações promove a descontinuidade do pensamento ou, ainda, a transição brusca de uma ideia à outra, provocando o desinteresse e desestímulo pela discussão.

É de crucial importância que se considerem as transições como uma evolução da discussão. Para que a tentativa de tratar questões diferentes não seja frustrada, os autores recomendam como quarto método de direção da discussão a divisão das questões a serem tratadas. Dividir as questões é uma estratégia de organização a fim de evitar desordem e confusão. Não só as questões pedem uma divisão que organize, mas também uma mesma questão com muitas facetas de interesse para o grupo. Essa tarefa de divisão de questões em itens específicos é tarefa do líder. Sendo bem elaborada, a divisão das questões amplas dará maior unidade à discussão e consolidará [...] o caminho para o reconhecimento de concordâncias e dissensões que, de outro modo, poderiam não ocorrer (p. 294). 
O esclarecimento da discussão é outro recurso apresentado pelos autores como garantidores de ordem, direção e sentido da discussão. Isso pode ser elaborado a partir do que os autores chamaram "sumários ocasionais". Nesses documentos registram-se as áreas ainda não cobertas, o que permite, após uma digressão, voltar ao ponto de referência. O sumário permite, outrossim, a inversão da ordem na discussão sem perdas já que a retomada é sempre possível. Os assuntos adiados podem ainda ser revisados e enriquecidos com contribuições mais tarde, assim como é possível retomar posições pouco claras apresentadas anteriormente. O líder pode se servir desses recursos com a finalidade de reunir num todo as contribuições diversas apresentadas, atribuindo-Ihes um sentido.

\section{CONSIDERAÇÕES FINAIS}

A fim de verificarmos a distinção entre os conceitos que circundam os termos discussão e debate, foi feita uma leitura da obra de M\&H. Durante a leitura nos foram apresentadas quatro relações básicas que definem o fundamento da discussão. Bem como as cinco definições sugeridas e estudadas pelos autores. 0 pensamento reflexivo é citado como fundamental para a construção da discussão. Os autores citam elementos que constituem o "bom discurso" dando ênfase a atitude e ao comportamento do orador diante da plateia. É importante ressaltar que os participantes da discussão devem estar envolvidos com o problema a ser analisado. Pois, como pudemos perceber, a atitude de todos os participantes é o ponto fundamental nesse processo. Na condução do processo existem algumas importantes atitudes que devem ser levadas em consideração. O discurso precisa ser homogêneo, cada participante deve assumir sua responsabilidade diante do grupo, a manifestação de ideias deve ser na medida, não deixar que a discussão tome caminhos pessoais. A partir daí os autores citam o contexto e as informações complementares. Logo em seguida, as suposições que entendemos como uma atitude que está presente em todas as discussões e que nos remetem para a argumentação.

Com relação à atitude do líder do grupo são apontados alguns elementos como desenvolver o interesse do grupo pelo assunto e mostrar o objetivo da discussão, ter clareza sobre o assunto a ser discutido, dar autonomia ao grupo e reconhecer que cada líder obtém seus melhores resultados de formas diferentes, pois cada um age de acordo com sua personalidade. O líder deve, ainda, assumir e manter uma postura coerente e segura desde o início da discussão. Para tanto são apresentados métodos para a abertura da discussão: a apresentação e interpretação da pergunta lançada, demonstração de um conjunto de questões específicas sobre o problema, a apresentação sintetizada de um tema geral a ser discutido, a definição inicial do problema, a relevância de citar alguns exemplos e o uso de choque de 


\section{DEE Debates \\ em Educação Científica e Tecnológica

opiniões de maneira acertada sem criar uma situação de simples oposição. Cabe ao líder oferecer subsídios para uma discussão bem orientada para que se chegue a um resultado estimulante e adequado. Ao final da leitura, podemos dizer que o pensamento reflexivo é uma marca forte da discussão, pois será através desse pensamento que o grupo poderá expor suas opiniões e sugestões acerca do problema. Sabendo disso, podemos sinalizar para a característica básica do líderorador que é conhecer o assunto a ser tratado e assumir uma postura que demonstre segurança e coerência.

\section{REFERÊNCIAS}

DASHIELL, J. F. A handbook of social psychology. Worcester, MA, US: Clark University Press, 1935.

DEWEY, John. How we think. New York: D.C. Heath \& Co. Disponível em: https://archive.org/stream/howwethink000838mbp\#page/n7/mode/2up. Acesso em: 17/05/2016.

LEFEVRE, F.; LEFEVRE, A. M. C. O discurso do sujeito coletivo: um novo enfoque em pesquisa qualitativa. Caxias do Sul: Educs, 2003.

MCBURNEY, J. H.; HANCE, K. G. Discussion in Human Affairs. New York: Harper \& Brothers, 1950. 